\title{
Life as an evacuee after the Fukushima Daiichi nuclear power plant accident is a cause of polycythemia: the Fukushima Health Management Survey
}

Akira Sakai ${ }^{1,1 *}$, Tetsuya Ohira ${ }^{2,11}$, Mitsuaki Hosoya ${ }^{3,11}$, Akira Ohtsuru ${ }^{4,11}$, Hiroaki Satoh ${ }^{5,11}$, Yukihiko Kawasaki ${ }^{3,11}$, Hitoshi Suzuki ${ }^{6,11}$, Atsushi Takahashi ${ }^{7}, 11$, Gen Kobashi ${ }^{8}$, Kotaro Ozasa ${ }^{9}$, Seiji Yasumura ${ }^{10,11}$, Shunichi Yamashita ${ }^{11,12}$, Kenji Kamiya ${ }^{11,13}$, Masafumi Abe ${ }^{11}$ and for the Fukushima Health Management Survey Group

\begin{abstract}
Background: The Great East Japan Earthquake and the Fukushima Daiichi nuclear disaster forced people to evacuate their hometowns. Many evacuees from the government-designated evacuation zone were forced to change their lifestyle, diet, exercise, and other personal habits. The Comprehensive Health Check (CHC), 1 of 4 detailed surveys of The Fukushima Health Management Survey (FHMS), was implemented to support the prevention of lifestyle-related disease. The aim of this study was to analyze changes in red blood cell count (RBC), hemoglobin ( $\mathrm{Hb}$ ) levels, and hematocrit $(\mathrm{Ht})$ levels by comparing data from the medical health checkup before and after the disaster in individuals who were 40 years old or older.
\end{abstract}

Methods: Subjects in this study were Japanese men and women living in the vicinity of the Fukushima Daiichi Nuclear Power Plant in Fukushima prefecture. Annual health checkups with a focus on metabolic syndrome for insured persons/dependents aged 40 or older by Health Care Insurers have been conducted since 2008. All analyses in this study were limited to men and women aged 40-90 years. Changes in RBC, Hb levels, Ht levels, and prevalence of polycythemia before and after the disaster were compared.

Results: First, RBC, Hb, and Ht significantly increased in both men and women evacuees. The evacuation was significantly associated with increased $\mathrm{Hb}$ levels after adjustment for age, gender, smoking status, excess ethanol intake, BMI, and baseline Hb level $(\beta=0.16, p<0.001)$. Furthermore, the prevalence of polycythemia stratified by smoking status or obesity also increased in the evacuee group.

Conclusions: To our knowledge, this is the first report revealing that the evacuation was associated with the risk of polycythemia. This information could be very important for periodic health checkup and lifestyle recommendations for evacuees in the future.

Keywords: Evacuee, Polycythemia, Fukushima Daiichi Nuclear Power Plant accident, Lifestyle-related disease, The Fukushima Health Management Survey

\footnotetext{
*Correspondence: sakira@fmu.ac.jp

'Department of Radiation Life Sciences, Fukushima Medical University School

of Medicine, 1 Hikarigaoka, Fukushima 960-1295, Japan

${ }^{11}$ Radiation Medical Science Center for the Fukushima Health Management

Survey, Fukushima Medical University School of Medicine, Fukushima, Japan

Full list of author information is available at the end of the article
} 


\section{Background}

The Great East Japan Earthquake that occurred on 11 March 2011 and the Fukushima Daiichi nuclear disaster forced people to evacuate their hometowns with notice, caused them to change their lifestyle to fit a completely new situation, and produced anxiety about radiation. In response to concerns about the effects these factors could have on health, the Comprehensive Health Check (CHC), 1 of 4 detailed surveys of the Fukushima Health Management Survey (FHMS), was implemented to support the early detection and treatment of disease as well as the prevention of lifestyle-related diseases, such as heart disease and cerebrovascular disease.

Japan experienced atomic bombings in Hiroshima and Nagasaki in 1945. In 1947, the Atomic Bomb Casualty Commission $(\mathrm{ABCC})$ was established to investigate the health impacts on atomic bomb (A-bomb) survivors. Later, a large-scale cohort study of survivors was started in order to investigate the long-term stochastic effects of radiation. The ABCC had continued follow-up surveys through the present time [1-3]. In April 1986, the worst nuclear disaster in human history occurred at the Chernobyl Nuclear Power Plant. The accident released a large quantity of radioactive material into the atmosphere. The USSR Ministry of Health started the Russian National Medical and Dosimetric Registry in June the same year to resister residents exposed to radiation. However, an epidemiologic study evaluating long-term radiation effects on public health was unfortunately not implemented soon enough after the accident [4].

The primary purposes of the FHMS are to monitor the long-term health of residents, promote their future wellbeing, and determine whether long-term low-dose radiation exposure has health effects. The FHMS consists of a basic survey and 4 detailed surveys, namely, thyroid ultrasound examination, comprehensive health check, a mental health and lifestyle survey, and a pregnancy and birth survey [5]. Many evacuees from the governmentdesignated evacuation zone were forced to change their lifestyle, diet, exercise, and other personal habits. Some could not receive adequate health checks, and some had anxieties about their health [6]. The CHC attempts to review their health information, assess the incidence of various diseases, and improve their health status. Here we focused on changes in red blood cell count before and after the disaster.

\section{Methods}

\section{Subjects}

Subjects in this study were Japanese men and women living in the vicinity of the Fukushima Daiichi Nuclear Power Plant in Fukushima prefecture; Tamura, MinamiSoma, Kawamata, Hirono, Naraha, Tomioka, Kawauchi, Okuma, Futaba, Namie, Katsurao, Iitate, and Date. All residents of Hirono, Naraha, Tomioka, Kawauchi, Okuma, Futaba, Namie, Katsurao, and litate, and part of residents of Tamura, Minami-Soma, Kawamata, and Date were forced to evacuate their homes due to the governmental direction after the disaster. In these communities, annual health checkups with a focus on metabolic syndrome for insured persons/dependents aged 40 or older by Health Care Insurers have been conducted since 2008. All analyses in this study were limited to men and women aged 40-90 years. Between 2008 and 2010, 41,633 men and women (18,745 men and 22,888 women, mean 67 years) in the communities participated in the health checkups. The initial exclusion criteria were persons without peripheral blood hemoglobin $(\mathrm{Hb})$ data $(n=23,279)$ and those with a past history of or who were being treated for hematologic disease or residents undergoing dialysis due to renal impairment $(n=107)$. The remaining data of 18,247 men and women (7,647 men and 10,709 women, mean 68 years) were used for the analyses as a baseline data. Informed consent was obtained from the community representatives to conduct an epidemiological study based on guidelines of the Council for International Organizations of Medical Science [7]. This study was approved by the Ethics Committee of the Fukushima Medical University School of Medicine (approval number 1916).

Follow-up examinations were conducted between 2011 and 2012 as a part of the CHC. Detailed methods of the $\mathrm{CHC}$ was described by Yasumura previously [5]. Basically, this $\mathrm{CHC}$ performed health examinations for individuals of all ages living in the evacuation zone designated by the government, who were officially registered residents at the time of the earthquake. 10,718 men and women (4,627 men and 6,091 women, follow-up rate: 59\%) received the follow-up examination after the disaster, and an average follow up was 1.6-year. There were some differences in baseline characteristics between individuals who received follow-up examinations and those who did not, such as mean age (67.4 vs 69.7 years) and prevalence of diabetes mellitus (10.3\% vs $12.4 \%)$ and hypertension $(55.5 \%$ vs $60.2 \%$ ), while there were no differences in baseline BMI and smoking status. Baseline characteristics of individuals who received the follow-up examinations are shown in Table 1.

\section{Measurements}

Individuals aged 16 years or older are evaluated according to items in the Specific Health Examination based on the Act on Assurance of Medical Care for Elderly People (Act No. 80, 1982). The items are listed in Additional file 1: Table S1. Additional items for assessment include serum creatinine $(\mathrm{Cr})$, estimated glomerular filtration rate (eGFR), uric acid (UA), urine testing for occult blood, and peripheral blood count, which includes red blood cell count (RBC), hematocrit (Ht), Hb, platelet count, and white 
Table 1 Means or prevalence for baseline characteristics of participants in this study

\begin{tabular}{|c|c|c|c|c|c|}
\hline \multirow[b]{2}{*}{ Baseline characteristics } & \multicolumn{5}{|c|}{ Total $(n=10,718)$} \\
\hline & \multicolumn{2}{|c|}{ Evacuees } & \multicolumn{2}{|c|}{$\begin{array}{l}\text { Non- } \\
\text { evacuees }\end{array}$} & \multirow[t]{2}{*}{$p$ value $* * *$} \\
\hline$n$ & 7,4463 & & 3,272 & & \\
\hline Age (years) & 66.3 & $\pm 9.8^{* *}$ & 69.8 & $\pm 8.8^{* *}$ & 0.01 \\
\hline Sex (\% women) & 56.0 & & 58.8 & & $<0.01$ \\
\hline Body mass index $\left(\mathrm{kg} / \mathrm{m}^{2}\right)$ & 23.7 & $\pm 3.3^{* *}$ & 23.4 & $\pm 3.3^{* *}$ & $<0.01$ \\
\hline Overweight* (\%) & 31.8 & & 28.9 & & $<0.01$ \\
\hline Hypertension (\%) & 54.5 & & 57.7 & & $<0.01$ \\
\hline Diabetes Mellitus (\%) & 10.7 & & 9.4 & & 0.04 \\
\hline Current smoker (\%) & 12.8 & & 10.2 & & $<0.001$ \\
\hline Current drinker (\%) & 23.7 & & 20.5 & & $<0.001$ \\
\hline
\end{tabular}

*Body mass index $\geq 25.0 \mathrm{~kg} / \mathrm{m}^{2}$; **Standard deviaion; ***Student t-tests or chi-squared tests.

blood cell (WBC) count with subpopulations of white cells. All peripheral blood cell counts before and after the disaster were measured using the Autoanalyzer XN9000 (Sysmex Co. Inc., Kobe, Japan) at the laboratory of the Fukushima Preservative Service Association of Health, except for residents in Futaba $(n=702)$. Since the trends in blood cell counts before and after the disaster in Futaba were essentially same as other communities, we included the data of Futaba to analyze. In the $\mathrm{CHC}$, the definition of anemia is $\mathrm{Hb}$ less than $13.0 \mathrm{~g} / \mathrm{dL}$ in men and less than $12.0 \mathrm{~g} / \mathrm{dL}$ in women. The definition of polycythemia is $\mathrm{Hb}$ of $18.0 \mathrm{~g} / \mathrm{dL}$ or more in men and $16.0 \mathrm{~g} / \mathrm{dL}$ or more in women.

\section{Statistical analysis}

Means or prevalence for baseline variables of interest were compared between the evacuees $(n=7,446)$ and non-evacuees $(\mathrm{n}=3,272)$ using Student $\mathrm{t}$-tests or chisquared tests. Changes in RBC, Hb levels, Ht levels, and prevalence of polycythemia before and after the disaster were compared using a Student's paired $t$ test or McNemer's test. Analysis of covariance (ANCOVA) was used to examine the differences in the variables between the evacuees and non-evacuees adjusted for age (years), gender, and smoking status. Multiple linear regression analysis was used to test for associations of evacuation and other potential confounders with change in $\mathrm{Hb}$, and the fit of models was tested using residual analysis. The potential confounders were age (years), gender, smoking status, excess ethanol intake ( $\geq 44 \mathrm{~g} /$ day), BMI, and baseline $\mathrm{Hb}$ level (Model 1), and further adjustment for change in BMI before and after the disaster (Model 2). Furthermore, logistic regression analysis was used to test for association of evacuation with newly-developing polycythemia after the disaster adjusting for the potential confounders.

SAS version 9.3 (SAS Institute, Cary, North Carolina, USA) was used for analyses. All probability values for statistical tests were 2-tailed and $p$ values of less than 0.05 were regarded as statistically significant.

\section{Results and discussion}

On implementing the $\mathrm{CHC}$, we expected that there were no individuals with the risk of cytopenia according to the results of estimation of external dose in the FHMS $[8,9]$. Furthermore, because the comparable items in the peripheral blood count before and after the disaster were $\mathrm{RBC}, \mathrm{Hb}$, and $\mathrm{Ht}$, we analyzed the change in those items. Changes in lifestyle among evacuees caused increases in body weight and blood pressure [10]. Therefore, we expected that it would cause polycythemia as well. The standard values for peripheral blood in the $\mathrm{CHC}$ are as follows: RBC $400-579 \times 10^{4} / \mu \mathrm{L}, \mathrm{Hb} 13.1-17.9 \mathrm{~g} / \mathrm{dL}$, and Ht $38.0-54.9 \%$ in men; RBC $370-549 \times 10^{4} / \mu \mathrm{L}$, Hb 12.1 $15.9 \mathrm{~g} / \mathrm{dL}$, and Ht $33.0-47.9 \%$ in women. As for the diagnosis of polycythemia, one of these items is beyond the standard value.

First, $\mathrm{RBC}, \mathrm{Hb}$, and $\mathrm{Ht}$ significantly increased in both men and women evacuees (Table 2). Furthermore, ageadjusted $p$ value for comparing the changes of these items in the evacuee group to those in the non-evacuee group between before and after the earthquake was

Table 2 Changes in RBC, $\mathrm{Hb}$, and $\mathrm{Ht}$ according to evacuation status

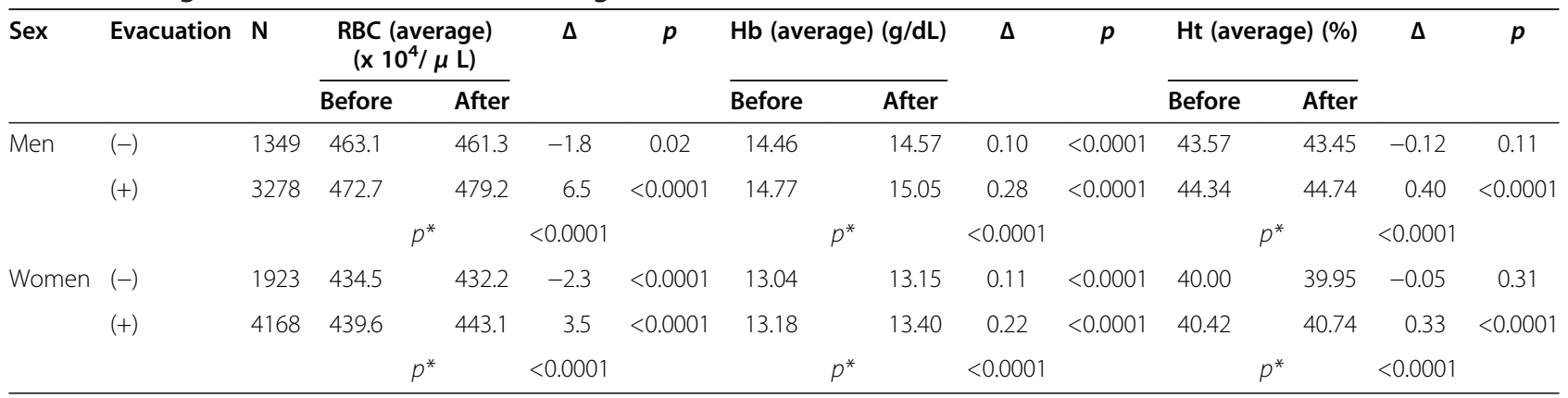

*Age-adjusted $p$ value for comparing changes in the evacuee group to changes in the non-evacuee group before and after the earthquake. $\mathrm{RBC}$, red blood cell count: $\mathrm{Hb}$, hemoglobin; Ht. hematocrit. 
significant (Table 2). Next we performed a multivariate analysis to find whether the evacuation was an independent factor for an increase in $\mathrm{Hb}$ in the presence of smoking, one of the important causes of polycythemia, and obesity and weight gain, which were already reported to be related to the evacuation [9]. The evacuation was significantly associated with increased $\mathrm{Hb}$ levels after adjustment for age, gender, smoking status, excess ethanol intake, BMI, and baseline $\mathrm{Hb}$ level $(\beta=0.16, p<0.001)$. In the present study, mean levels of BMI of the participants increased from $23.6 \mathrm{~kg} / \mathrm{m}^{2}$ to $24.0 \mathrm{~kg} / \mathrm{m}^{2}$ before and after the disaster $(p<0.001)$. The association between evacuation and increased $\mathrm{Hb}$ levels was attenuated after further adjustment for change in BMI before and after the disaster, but it remained statistically significance $(\beta=0.11, p<$ 0.001). Furthermore, increasing of $\mathrm{Hb}$ levels in the present study might not be influenced by change in proportion of smoking status because the proportion of smokers decreased after the disaster in both evacuees and nonevacuees; from $12.8 \%$ to $11.9 \%$ for evacuees and from $10.2 \%$ to $8.4 \%$ for non-evacuees.

In this study the standard values of obesity and the significant weight gain are a BMI of $25 \mathrm{~kg} / \mathrm{m}^{2}$ or more and an increase in BMI of $1 \mathrm{~kg} / \mathrm{m}^{2}$ or more, respectively. We also analyzed age-adjusted $p$ values for comparing the changes in $\mathrm{Hb}$ in the evacuee group to those in the non-evacuee group between before and after the earthquake because the value of $\mathrm{Hb}$ is a representative index of polycythemia (Table 3). In men, the evacuation significantly influenced an increase in $\mathrm{Hb}$ regardless of smoking status, and the group that did not smoke showed a more significant increase. In the relationship between the changes in $\mathrm{Hb}$ and BMI or increase in BMI, the evacuation had a significant influence on the group with BMI less than $25 \mathrm{~kg} / \mathrm{m}^{2}$ and increase of less than $1 \mathrm{~kg} / \mathrm{m}^{2}$ in BMI. In women, the evacuation significantly influenced an increase in $\mathrm{Hb}$ in the group that did not smoke. The evacuation increased the value of $\mathrm{Hb}$ regardless of obesity, and the increase in $\mathrm{Hb}$ was significantly higher in the group with BMI less than $25 \mathrm{~kg} / \mathrm{m}^{2}$. Furthermore, the evacuation was followed by a significant increase in $\mathrm{Hb}$ in the group with less than $1 \mathrm{~kg} / \mathrm{m}^{2}$ increase in BMI. These results revealed that life as an evacuee leads to increase in $\mathrm{Hb}$. However, what is especially important is whether an incidence of polycythemia in the evacuee group, but not in the non-evacuee group, significantly increased after the disaster. Prevalence of polycythemia before and after the disaster were $0.79 \%$ and $1.16 \%$ for the non-evacuees $(p=0.10)$ and $0.89 \%$ and $1.54 \%$ for the evacuees $(p<0.001)$, respectively. Then, we further analyzed the prevalence of polycythemia stratified by smoking status or obesity, the tendency was virtually unchanged (Table 4). Among smokers, prevalence of polycythemia before and after the disaster were $1.19 \%$ and $1.79 \%$ for the non-evacuees $(p=0.50)$ and $1.89 \%$ and $3.67 \%$ for the evacuees $(p<0.01)$, and among nonsmokers, those of polycythemia were $0.75 \%$ and $1.09 \%$ for the non-evacuees $(p=0.16)$ and $0.74 \%$ and $1.23 \%$ for the evacuees $(p<0.001)$, respectively. Among obese, prevalence of polycythemia before and after the disaster were $1.06 \%$ and $1.59 \%$ for the non-evacuees $(p=0.36)$ and $1.48 \%$ and $2.45 \%$ for the evacuees $(p<0.01)$, and among non-obese, those of polycythemia were $0.69 \%$ and $0.99 \%$ for the non-evacuees $(p=0.23)$ and $0.61 \%$ and $1.12 \%$ for the evacuees $(p<0.001)$, respectively. Based on these results, we suggest that the evacuation is an independent factor for polycythemia regardless of smoking status, obesity, or weight gain, while an logistic regression

Table 3 Influence of the evacuation on changes of $\mathrm{Hb}$ in relation to smoking, obesity, and weight gain

\begin{tabular}{|c|c|c|c|c|c|}
\hline \multirow[t]{2}{*}{ Sex } & \multirow[t]{2}{*}{ Factors } & \multirow[t]{2}{*}{$\mathbf{n}$} & \multicolumn{2}{|c|}{ Changes in $\mathrm{Hb}(\mathrm{g} / \mathrm{d})$} & \multirow[t]{2}{*}{$p^{*}$} \\
\hline & & & Evacuation (-) & Evacuation (+) & \\
\hline \multirow[t]{6}{*}{ Men } & Smoking (-) & 3,579 & 0.11 & 0.29 & $<0.0001$ \\
\hline & Smoking $(+)$ & 1,048 & 0.09 & 0.27 & 0.008 \\
\hline & $\mathrm{BMl}<25 \mathrm{~kg} / \mathrm{m}^{2}$ & 3,180 & 0.10 & 0.30 & $<0.0001$ \\
\hline & BMI $25 \geqq \mathrm{~kg} / \mathrm{m}^{2}$ & 1,447 & 0.13 & 0.24 & 0.08 \\
\hline & Change in $\mathrm{BM}<1 \mathrm{~kg} / \mathrm{m}^{2}$ & 2,981 & 0.03 & 0.15 & 0.006 \\
\hline & Change in $\mathrm{BM} \geqq 1 \mathrm{~kg} / \mathrm{m}^{2}$ & 1,646 & 0.44 & 0.46 & 0.89 \\
\hline \multirow[t]{6}{*}{ Women } & Smoking $(-)$ & 5,851 & 0.12 & 0.22 & $<0.0001$ \\
\hline & Smoking (+) & 240 & -0.04 & 0.13 & 0.12 \\
\hline & $\mathrm{BMI}<25 \mathrm{~kg} / \mathrm{m}^{2}$ & 4,229 & 0.12 & 0.22 & 0.0002 \\
\hline & $\mathrm{BMI} 25 \geqq \mathrm{~kg} / \mathrm{m}^{2}$ & 1,862 & 0.10 & 0.21 & 0.02 \\
\hline & Change in $\mathrm{BM}<1 \mathrm{~kg} / \mathrm{m}^{2}$ & 4,444 & 0.09 & 0.17 & 0.002 \\
\hline & Change in $B M \geqq 1 \mathrm{~kg} / \mathrm{m}^{2}$ & 1,647 & 0.22 & 0.31 & 0.13 \\
\hline
\end{tabular}

${ }^{*}$ Age-a djusted $p$ value for comparing changes in the evacuee group to changes in the non-evacuee group before and after the earthquake. $\mathrm{BMI}$, body math index; $\mathrm{Hb}$, hemoglobin. 
Table 4 Influence of the evacuation on prevalence of polycythemia in relation to smoking and obesity

\begin{tabular}{|c|c|c|c|c|c|c|}
\hline & & & & Before & 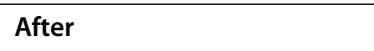 & $p^{*}$ \\
\hline & & & $\mathbf{n}$ & Number of polycythemia (\%) & Number of polycythemia (\%) & \\
\hline \multirow[t]{2}{*}{ Total } & & Evaculation (-) & 3,272 & $26(0.79)$ & $38(1.16)$ & 0.10 \\
\hline & & Evaculation (+) & 7,446 & $66(0.89)$ & $115(1.54)$ & $<0.001$ \\
\hline \multirow[t]{4}{*}{ Obese } & + & Evaculation (-) & 945 & $10(1.06)$ & $15(1.59)$ & 0.36 \\
\hline & & Evaculation $(+)$ & 2,364 & $35(1.48)$ & $58(2.45)$ & $<0.01$ \\
\hline & - & Evaculation (-) & 2,327 & $6(0.69)$ & $23(0.99)$ & 0.23 \\
\hline & & Evaculation (+) & 5,082 & $31(0.61)$ & $57(1.12)$ & $<0.001$ \\
\hline \multirow[t]{4}{*}{ Smoking } & + & Evaculation (-) & 335 & $4(1.19)$ & $6(1.79)$ & 0.50 \\
\hline & & Evaculation (+) & 953 & $18(1.89)$ & $35(3.67)$ & $0<0.01$ \\
\hline & - & Evaculation (-) & 2,973 & $22(0.75)$ & $32(1.09)$ & 0.16 \\
\hline & & Evaculation (+) & 6,493 & $48(0.74)$ & $80(1.23)$ & $<0.001$ \\
\hline
\end{tabular}

*McNemar's test for comparing changes in the prevalence of polycythemia in the evacuee and non-evacuee group before and after the earthquake.

analysis showed the association between evacuation and newly-developing polycythemia did not reach statistical significance; the multivariable adjusted odds ratio for evacuation is 1.11 (95\% confidence interval; 0.71-1.73).

Common causes of polycythemia are polycythemia vera (myeloproliferative disease), secondary polycythemia caused by diseases such as pulmonary heart disease that induce a chronic lack of oxygen or an erythropoietin-producing tumor, and relative polycythemia or stress-induced polycythemia. The mechanism of stress-induced polycythemia is unknown, and it is usually diagnosed in middle-aged men who smoke, are obesity, and have hypertension, or hyperuricemia. Although dehydration induced by use of diuretic for hypertension might affect $\mathrm{Hb}$ level, the difference of such a factor between evacuees and non-evacuees could not be clarified. To our knowledge, this is the first report showing that evacuation is a cause of polycythemia. Even in the group that was not evacuated, the value of $\mathrm{Hb}$ before and after the disaster increased significantly in both men and women (Table 2). Some kind of stress induced by the disaster might be causing the increase in $\mathrm{Hb}$ in this group.

The increase of lifestyle-related disease was expected because obesity, weight gain, and high blood pressure were shown to occur in evacuees after the disaster, and this investigation revealed that life as an evacuee causes polycythemia. Here we suggest that periodic health checkups and lifestyle guidance for evacuees in the future is very important.

\section{Conclusions}

In summary, $\mathrm{RBC}, \mathrm{Hb}$, and $\mathrm{Ht}$ significantly increased in both men and women evacuees. Furthermore, the prevalence of polycythemia also increased in the evacuee group. Periodic health checkups and lifestyle guidance should be carefully planned for evacuees.

\section{Appendix}

The Fukushima Health Management Survey Group

Masafumi Abe, Shunichi Yamashita, Kenji Kamiya, Seiji Yasumura, Mitsuaki Hosoya Akira Ohtsuru, Akira Sakai, Shinichi Suzuki, Hirooki Yabe, Masaharu Maeda, Shirou Matsui, Keiya Fujimori, Tetsuo Ishikawa, Tetsuya Ohira, Tsuyoshi Watanabe, Shigeatsu Hashimoto, Kenneth Eric Nollet, Shinichi Niwa, Yoshisada Shibata.

\section{Additional file}

Additional file 1: Table S1. Items included in comprehensive health check.

Competing interests

The authors declare that they have no competing interests.

\section{Authors' contributions}

AS and TO designed the study and contributed to writing the manuscript. TO also performed data collection and statistical analysis. MH, AO, HS, YK, HS, AT, GK, KO, and SY contributed to planning the health screening program. SY, KK, and MA contributed to scientific review. All authors read and approved the final manuscript.

\section{Acknowledgments}

This survey was supported by the National Health Fund for Children and Adults Affected by the Nuclear Incident. The findings and conclusions of this article are solely the responsibility of the authors and do not represent the official views of the Fukushima Prefecture government.

\section{Author details}

'Department of Radiation Life Sciences, Fukushima Medical University School of Medicine, 1 Hikarigaoka, Fukushima 960-1295, Japan. ${ }^{2}$ Department of Epidemiology, Fukushima Medical University School of Medicine, Fukushima, Japan. ${ }^{3}$ Department of Pediatrics, Fukushima Medical University School of Medicine, Fukushima, Japan. ${ }^{4}$ Department of Radiation Health Management, Fukushima Medical University School of Medicine, Fukushima, Japan. ${ }^{5}$ Department of Nephrology, Hypertension, Diabetology, and Endocrinology, Fukushima Medical University School of Medicine, Fukushima, Japan. ${ }^{6}$ Department of Cardiology and Hematology, Fukushima Medical University School of Medicine, Fukushima, Japan. ${ }^{7}$ Department of Gastroenterology and Rheumatology, Fukushima Medical University School of Medicine, Fukushima, Japan. ${ }^{8}$ Department of Planning and Management, National Institute of Radiological Sciences, Chiba, Japan. ${ }^{9}$ Department of Epidemiology, Radiation Effects Research Foundation, Hiroshima, Japan. ${ }^{10}$ Department of Public 
Health, Fukushima Medical University School of Medicine, Fukushima, Japan.

${ }^{11}$ Radiation Medical Science Center for the Fukushima Health Management

Survey, Fukushima Medical University School of Medicine, Fukushima, Japan.

${ }^{12}$ Japan and Atomic Bomb Disease Institute, Nagasaki University, Nagasaki,

Japan. ${ }^{13}$ Department of Experimental Oncology, Research Institute for

Radiation Biology and Medicine, Hiroshima University, Hiroshima, Japan.

Received: 27 May 2014 Accepted: 15 December 2014

Published: 23 December 2014

\section{References}

1. The Radiation Effects Research Foundation. A brief description available from: http://www.rerf.or.jp/shared/briefdescript/briefdescript.pdf.

2. Shigematsu I: lonizing radiation and health. J Epidemiol 1992, 2(2 Suppl):S21-9.

3. Kodama K, Mabuchi K, Shigematsu I: A long-term cohort study of the atomic-bomb survivors. J Epidemiol 1996, 6(3 Suppl):S95-105.

4. Bennett B, Repacholi M, Carr Z: Health effects of the Chernobyl accident and special health care programmes. Report of the UN Chernobyl Forum Expert Group "Health". Geneva: World Health Organization; 2006.

5. Yasumura S, Hosoya M, Yamashita S, Kamiya K, Abe M, Akashi M, Kodama K, Ozasa K for the Fukushima Health Management Survey Group: Study protocol for the Fukushima Health Management Survey. J Epidemiol 2012, 22(5):375-383.

6. Sugimoto A, Krull S, Nomura S, Morita T, Tsubokura M: The voice of the most vulnerable: lessons from the nuclear crisis in Fukushima, Japan. Bull World Health Organ 2012, 90(8):629-630.

7. International guidelines for ethical review of epidemiological studies. Law Med Health Care 1991, 19(3-4):247-258.

8. Nagataki S, Takamura N, Kamiya K, Akashi M: Measurements of individual radiation doses in residents living around the Fukushima nuclear power plan. Radiation Res 2013, 180:439-447.

9. Tenth YS, Warrent K: Sinclair Keynote address: the Fukushima nuclear power plant accident and comprehensive health risk management. Health Phys 2014, 106(2):166-180.

10. Fukushima Radiation and Health. Survey results available from http://www. fmu.ac.jp/radiationhealth/results/.

doi:10.1186/1471-2458-14-1318

Cite this article as: Sakai et al.: Life as an evacuee after the Fukushima Daiichi nuclear power plant accident is a cause of polycythemia: the Fukushima Health Management Survey. BMC Public Health 2014 14:1318.

\section{Submit your next manuscript to BioMed Central and take full advantage of:}

- Convenient online submission

- Thorough peer review

- No space constraints or color figure charges

- Immediate publication on acceptance

- Inclusion in PubMed, CAS, Scopus and Google Scholar

- Research which is freely available for redistribution 